\title{
Assessment of Genetic Variation within Commercial Iranian Pomegranate (Punica granatum L.) Cultivars, Using ISSR and SSR Markers
}

\author{
Meysam Madadi*, Zabihollah Zamani, Reza Fatahi \\ Department of Horticultural Sciences, Faculty of Agriculture, University of Tehran, Karaj, Iran
}

\begin{tabular}{l}
\hline A R T I C L E I N F O \\
Research Article \\
Received 26 November 2016 \\
Accepted 30 May 2017 \\
\hline
\end{tabular}

Keywords:

Punica granatum

Clone

Genetic diversity

ISSR

SSR

\begin{tabular}{l} 
*Corresponding Author: \\
\hline E-mail: madadim2002@gmail.com
\end{tabular}
\begin{abstract}
A B S T R A C T
Pomegranate is one of the most important horticultural crops in Iran, and has been cultivated for thousands of years in this country. At this period due to selection of superior cultivars from nature or mutation emerged in these cultivars, and their vegetative propagation, substantial genetic variation has occurred within and among the cultivars. Thus, each cultivar may consist of different clones. According to this issue, diversity within four commercial cultivars of pomegranate was analyzed. Two molecular marker systems including ISSR and SSR were used to evaluate variability between 36 samples of four commercial cultivars. ISSR markers produced 114 amplification products, out of which 97 were polymorphic (83.23\%). Mean resolving power was 2.96 for ISSR markers. 19 SSR molecular markers were used, 15 of which amplified polymorphic products, while the remaining ones monomorphic., The number of polymorphic alleles per locus ranged from two to four (average 3.6). The observed and expected heterozygosities ranged from 0.04 to 0.92 and 0.14 to 0.62 , respectively. In addition, mean polymorphic information content was 0.45 for SSR loci. Our results showed that commercial Iranian pomegranate have different clones. Therefore, ISSR and SSR markers can be a useful tools for detecting clones of each cultivar.
\end{abstract}

DOI: https://doi.org/10.24925/turjaf.v5i6.622-628.1100

\section{Introduction}

Pomegranate (Punica granatum L.) is one of the oldest known edible fruits. It is among fruit species mentioned in the Holy Quran and is capable of growing in different agro-climatic conditions ranging from the tropical to sub-tropical regions due to versatile adaptability, hardy nature, low cost maintenance and high returns. Botanically, the pomegranate is included in the family Punicaceae with $2 \mathrm{n}=16$ or 18 . The genus Punica is known to include two species, namely $P$. protopunica and $P$. granatum (Mars, 2000). Although, it is native of Iran, it is cultivated extensively in the Mediterranean and central Asian countries. Pomegranate is also important in human medicine and its components have a wide range of clinical applications. The anthocyanin from pomegranate fruits have been shown to have higher antioxidant activity than vitamin $\mathrm{E}$, vitamin $\mathrm{C}$ or carotene (Shukla et al. 2008). Moreover, commercial pomegranate juice has been shown to have three times higher antioxidant activity than green tea and red wine (Gil et al. 2000). Iran as a center of pomegranate growth possesses more than 760 genotypes which have been collected and maintained in Yazd and Saveh germplasm (Behzadi-Shahrebabaki, 1998), Among them there have been multiple homonyms and synonyms, therefore a comprehensive plan to identify the genotypes is essential., This problem has been observed in the commercial Iranian pomegranate, where a pomegranate cultivar has different names in various regions and several different genotypes are known by the same name. In addition, due to the long historical cultivation and various environmental conditions in which, these cultivars are growing, natural mutations is expected to occur in some genotypes and caused genetic variability in different genotypes. Some of these mutations can be very useful, so that the mutant genotypes have desirable traits and it can be a significant improvement in performance and product quality of a particular genotype.

Molecular markers have overcome the limitations of morphological and biochemical markers due to avoiding the influence of environment on the performance of genotypes. A wide range of molecular markers has been used to assess genetic diversity of pomegranate cultivars as well as wild genotypes from different parts of the world. Random amplified polymorphic DNA (RAPD) markers have provided reliable and highly polymorphic information to discriminate pomegranate cultivars (Narzary et al., 2009; Hasnaoui et al., 2010a). AFLPs (Amplified Fragments Length Polymorphism) are another marker, which has been used to evaluate genetic diversity within and among Chinese pomegranate populations (Yuan et al., 2007) and Tunisian cultivars (Jbir et al., 2008). Up to now, more than 137 microsatellite loci in pomegranate genome have been identified (Soriano et al., 
2011; Curro et al., 2010; Hasnaoui et al., 2010b) showing different ranges of genetic polymorphism in the genotypes studied. Inter-Simple Sequence Repeats (ISSR) analysis is considered as another efficient molecular marker, showing genetic variation in the wild pomegranate populations studied in Western Himalaya region (Narzary et al., 2010; and Ajal et al., 2014). Morphological, cytological and DNA markers (RAPD, AFLP, SSR and ISSR) have been used to evaluate the genetic variability of Iranian pomegranates. These studies showed the occurrence of high genetic diversity among Iranian genotypes studied at both cytogenetic (Sheidai and Noormohammadi, 2005) and molecular levels including RAPD (Sarkhosh et al., 2006; Sheidai et al., 2007; Noormohammadi et al., 2010; Zamani et al. 2013), AFLP (Moslemi et al., 2010) and SSR markers (KoohiDehkordi et al., 2007; Pirseyedi et al., 2010; Ebrahimi et al., 2010). The present study was performed with the aim to identify genetic diversity within four commercial pomegranate cultivars of Iran and attempt to evaluate the usefulness of the two molecular markers (ISSR and SSR) that will help breeders to recognize superior cultivars for breeding programs.

\section{Materials and Methods}

\section{Plant Materials}

This work was carried out on 36 trees of four commercial pomegranate cultivars (each cultivar was represented by 9 trees or samples), plus 3 trees of the three non-commercial pomegranate genotypes as an out group (Black, Seedless white skin, Sweet white skin) to present other samples in realistic distances in clustering, from four different regions in Iran (Table 1).The nine trees were chosen from three different gardens and each garden included three samples. The trees were between 30 and 80 years-old, vigorous, almost uniform, and free from pathogens.

\section{DNA Isolation and ISSR Amplification}

Genomic DNA was extracted from the young leaves using Vroh Bi et al. (1996) method. PCR reactions were performed in $15 \mu \mathrm{l}$ total volumes containing $20 \mathrm{ng}$ of each template DNA, $0.3 \mu \mathrm{l}$ of primers, $8.5 \mu \mathrm{l}$ of PCR kit master mix (CinnaGen Co., Iran), and DNA-free water. Amplifications were performed in a thermocycler (iCycler, Bio Rad, Hercules, CA, USA) programmed for a first denaturation step of $4 \mathrm{~min}$ at $94^{\circ} \mathrm{C}$, followed by 35 cycles of $92^{\circ} \mathrm{C}$ for $1 \mathrm{~min}, 48-54^{\circ} \mathrm{C}$ (varied for each primer according to Table 2) for $50 \mathrm{~s}, 72^{\circ} \mathrm{C}$ for $1 \mathrm{~min}$ and final extension at $72^{\circ} \mathrm{C}$ for $10 \mathrm{~min}$ and then held at $4^{\circ} \mathrm{C}$ until the tubes were removed. Amplified products were separated by electrophoresis in $2 \%(\mathrm{w} / \mathrm{v})$ agarose gels at constant voltage $(80 \mathrm{~V})$ in $1 \times \mathrm{TBE}$ buffer for approximately 150-180 min, stained with ethidium bromide and photographed under UV light (Fig. 1). The size of produced fragments were determined by comparing to a size marker (GeneRuler 100bp DNA ladder, SM0313, Fermentase).

\section{SSR Amplification}

Amplification of microsatellites was performed in PCR reactions in a total volume of $20 \mu \mathrm{l}$, containing $20 \mathrm{ng}$ genomic DNA, 1X supplied PCR buffer (Bioron, Germany), $2 \mathrm{mM} \mathrm{MgCl}_{2}, 200 \mu \mathrm{M}$ of each dntp (Bioron, Germany), 1 unit of Taq DNA polymerase (Bioron, Germany) and $0.2 \mu \mathrm{M}$ of forward and reverse primers (fluorescently labeled). PCRs were carried out on a thermocycler (iCycler, Bio Rad, Hercules, CA, USA) programmed with a denaturation at $94^{\circ} \mathrm{C}$ for $5 \mathrm{~min}, 35$ cycles of $94^{\circ} \mathrm{C}$ for 1 min (varied for each primer according to Table $3,72^{\circ} \mathrm{C}$ for $1.5 \mathrm{~min}$ and final extension at $72^{\circ} \mathrm{C}$ for $15 \mathrm{~min}$, then restrain at $4^{\circ} \mathrm{C}$ until the tubes were removed. The PCR products were then denatured by the addition of $7.5 \mu \mathrm{l}$ formamide loading dye $(95 \%$ deionized formamide $10 \mathrm{mM}$ EDTA $\mathrm{pH} 8$, $0.05 \%$ xylene cyanol, $0.5 \%$ bromophenol blue), heated for $5 \mathrm{~min}$ at $94{ }^{\circ} \mathrm{C}$, cooled on ice and then $5 \mu \mathrm{l}$ for denatured preparations were loaded on a pre-warmed $\left(50^{\circ} \mathrm{C}\right)$ polyacrylamide sequencing gel (Bio Rad, SequiGen GT). Gels were run for 2-2.5 h at $75 \mathrm{~V}$ and the DNA banks were visualized by silver staining as described by Bassam and Caetano-Anolles (1993). A permanent record of gels was made using a gel scanner. The size of the produced bands was estimated by comparison to size marker (Fermentase Co.).

\section{ISSR and SSR Primers and Data Analysis}

Thirteen synthesized ISSR and fifteen SSR loci primers were used for polymorphism detection on the samples. A list of primers and their information are presented in Tables 2 and 3. Only reproducible and welldefined bands in the replications were considered as potential polymorphic markers. For ISSR primers the polymorphic bands were scored as present (1) or absent (0) and for SSR primers scoring alleles was performed as letters (A, B, C, D). In each sample for instance: the presence of $\mathrm{AA}$ as a homozygote and $\mathrm{AC}$ as a heterozygote on that location. A similarity matrix using the similarity coefficient of Jaccard (Sneath and Sokal, 1973) was constructed from the whole ISSR and SSR data. The similarity matrix was used for the cluster analysis and construction of dendrogram using unweighted pair-group method (UPGMA) (Sneath and Sokal, 1973) using the NTsys-pc version 2.02 (Rohlf, 2000). The total number of generated fragments, the number of polymorphic bands and polymorphism percentage were calculated by GenAlex 6.4 (Marshall et al., 1998) for each primer. The number of alleles, percentage of polymorphic loci, observed heterozygosity (Ho), Expected heterozygosity (He), and Polymorphic Information Content (PIC) were calculated based on frequency of alleles of each locus. POPGENE version 1.31 (Yeh et al., 1997), was used for these analyses. The ability of the most informative primers to differentiate the accessions was assessed by calculating their resolving power (Rp) (Prevost and Wilkinson, 1999) using the following formula (Gilbert et al., 1999): $\mathrm{R} p=\Sigma \mathrm{Ib}$ were $\mathrm{Ib}=1-(2 \times|0.5-p|)$, and $p$ is the proportion of the genotypes containing the present (1) band. 
Table 1 List of Pomegranate cultivars and their samples, codes and origin areas

\begin{tabular}{l|llll}
\hline \multirow{2}{*}{ Cultivar Names } & \multicolumn{1}{c}{ Origin } & \multicolumn{3}{c}{ Garden numbers with chosen codes } \\
\cline { 2 - 5 } Malas Saveh & Arak(Saveh) & Mls1, Mls2, Mls3 & Mls4, Mls5, Mls6 & Mls7, Mls8, Mls9 \\
Alek Yosef Khani & Arak(Saveh) & Alk1, Alk2, Alk3 & Alk4, Alk5, Alk6 & Alk7, Alk8, Alk9 \\
Ghojagh Qom & Qom & Gho1, Gho2, Gho3 & Gho4, Gho5, Gho6 & Gho7, Gho8, Gho9 \\
Chandab Varamin & Tehran(Varamin) & Chn1, Chn2, Chn3 & Chn4, Chn5, Chn6 & Chn7, Chn8, Chn9 \\
Black Pomegranate & Karaj & Black & - & - \\
Seedless white skin & Karaj & Seedless & - & - \\
Sweet white skin & Karaj & Sweet & - & - \\
\hline
\end{tabular}

Table 2 ISSR primers successfully used in this study and characteristic of primers

\begin{tabular}{l|lllcccc}
\hline \multicolumn{1}{c}{$\mathrm{R}$} & Primer & \multicolumn{1}{c}{ Sequence primer } & AT & TBN & NPB & PB & RP \\
\hline 1 & UBC810 & GAGAGAGAGAGAGAGAT & 52 & 6 & 4 & 66 & 2.05 \\
2 & UBC831 & CTCTCTCTCTCTCTCTT & 49 & 6 & 6 & 100 & 1.58 \\
3 & UBC868 & GAAGAAGAAGAAGAAGAA & 49 & 12 & 12 & 100 & 4.61 \\
4 & UBC873 & GACAGACAGACAGACA & 52 & 8 & 6 & 75 & 2.97 \\
5 & UBC880 & GGAGAGGAGAGGAGA & 52 & 8 & 7 & 87.5 & 1.38 \\
6 & ISO & ACACACACACACACACACC & 53 & 9 & 7 & 77.7 & 2.05 \\
7 & IS7 & ACGACGACGACGACGG & 50 & 11 & 11 & 100 & 5.48 \\
8 & IS8 & ACGACGACGACGACGC & 49 & 9 & 9 & 100 & 3.69 \\
9 & IS10 & TCGTCGTCGTCGTCGC & 48 & 8 & 7 & 87.5 & 4.92 \\
10 & IS13 & AGAGAGAGAGAGAGAGYT & 50 & 9 & 5 & 55.5 & 0.46 \\
11 & IS15 & ACACACACACACACACT & 52 & 4 & 3 & 75 & 0.40 \\
12 & IS23 & CTCCTCCTCCTCRC & 51 & 13 & 11 & 84.6 & 4.76 \\
13 & IS25 & GGATGGATGGATGGAT & 53 & 11 & 9 & 81.8 & 4.15 \\
\hline & Total & & & 8.7 & 7.4 & 83.23 & 2.96 \\
\hline
\end{tabular}

R: Row, AT: Annealing temperature $\left({ }^{\circ} \mathrm{C}\right)$; TBN: Total Band Number, NPB: Number of Polymorphic Band, PB: Polymorphic Band $(\%)$, RP: Resolving Power(Rp)

\section{Results and Discussion}

\section{ISSR Assay}

Thirteen ISSR primers produced 114 bands across the 39 samples, of which 97 were polymorphic. The number of amplified fragments varied from 4 (UBC-810) to 12 (UBC-868) across the samples. The average number of polymorphic bands per primer was 7.4. The percentage of polymorphism for primers ranged from 55.5 to 100 , with an average polymorphism percent of 83.23 (Table 2). Over the 13 primers, fragment sizes ranged from 200 to $1900 \mathrm{bp}$. The ability of the most informative primer to differentiate between samples was assessed using the Rp (Prevost and Wilkinson, 1999), whereby Rp values of primers varied from 0.04 (IS15) to 5.48 (IS7). The average $\mathrm{Rp}$ per primer was 2.96 . The similarity values varied from 0.27 for Gho4 versus Sweet to 0.89 for Mls6 and Mls7, respectively. A Jacard's similarity coefficient dendrogram based on matrix similarity analysis with ISSR data is presented in Figure 2 According to dendrogram, samples of Malas Saveh were separated into three (I) groups, when a similarity of 0.74 was considered Ghojagh's and Alak's samples in the resemblance of 67.5 were divided into 5 (II) and 6 (II) groups respectively. Chandab's samples in the similarity of 63 were detached into 4 (III)groups. In accordance with UPGMA clustering three of the out-group genotypes separated into two main clusters (Fig. 2).

\section{SSR Assay}

From 15 SSR primers, 35 alleles were identified (Table 3) The number of alleles obtained per locus varied from 2 (EPS06, EPS09, EPS19 and PGCT111) to 4 (PGCT109, PGCT080, PGCT088, PGCT093A and ABRII-MO26) with an average of 3.06 alleles per locus. The $\mathrm{Ho}$ and $\mathrm{He}$ ranged from 0.04 to 0.92 (mean value $=0.50$ ) and 0.14 to 0.62 (mean value $=0.56$ ), respectively. The PIC values ranged from 0.14 to 0.9 with an average of 0.45 . The size of the alleles products ranged from 147 to $237 \mathrm{bp}$. The Rp, used to determine the ability of primers to differentiate pomegranates, ranged from 0.3 (PGCT015) to 1.94 (PGCT080) (Table 4). Out of 15 polymorphic loci, 10 deviated significantly from the Hardy-Weinberg equilibrium (HWE) $(\mathrm{P}<0.05)$.

In the SSR similarity matrix, the highest and lowest similarity values were 0.96 (Between Chandab5 and 6) and 0.33 (Between Alak7 and Ghojagh6) respectively. The Jacard's similarity coefficient dendrogram obtained from SSR data is shown in Figure 3. With threshold similarity of 0.74 samples of Malas Saveh, Alak Yousef Khani and Chandab Varamin divided into 4, 8 and 5 (I) groups, respectively. When a similarity of 0.70 was considered, Ghojagh's samples separated into 6 (II) assemblies. The three out-group samples like the ISSR dendrogram divided into two groups. The seedless genotype was placed alone in a group in both clusters. 
Table 3 Characteristic of SSR loci.

\begin{tabular}{|c|c|c|c|c|}
\hline Locus Name & Repeat Motif & Primer sequence $\left(5^{\prime}-3^{\prime}\right)$ & $\mathrm{Ta}\left({ }^{\circ} \mathrm{C}\right)$ & Expected Product Size (bp) \\
\hline PGCT015 & $(\mathrm{CT})_{20}$ & $\begin{array}{l}\text { F: GACGCCTTTAGTTTGCTCCA } \\
\text { R: CTCGGGACAGGACTTGGAAT }\end{array}$ & 60 & 161 \\
\hline PGCT028 & $(\mathrm{CT})_{15}$ & $\begin{array}{l}\text { F: AAAAGCTGGCACTCAAACTC } \\
\text { R: GGCATTACTTCCAGGACAAC }\end{array}$ & 57 & 215 \\
\hline PGCT080 & $(\mathrm{GA})_{17}$ & $\begin{array}{l}\text { F: TGAGTGGAAGGGAAATAGGA } \\
\text { R:TCACCCTCTCCAAAATCAAA }\end{array}$ & 58 & 230 \\
\hline PGCT088 & $(\mathrm{CT})_{20}$ & $\begin{array}{l}\text { F: TCTCTCTCTACCCCGACACC } \\
\text { R: TAGCGTCAAGATTGTGAAAAGG }\end{array}$ & 56 & 150 \\
\hline PGCT109 & (CT) 18 & $\begin{array}{l}\text { F:GTAGCCACTTTAGGGCGAGA } \\
\text { R:CGTCTAAAAGCGACAGCAAG }\end{array}$ & 58 & 230 \\
\hline PGCT087 & (CT)24 & $\begin{array}{l}\text { F:GCCTTTTCCTGCTTTCCTTT } \\
\text { R:CATACAGCGGACCACAACAC }\end{array}$ & 60 & 181 \\
\hline PGCT093A & $(\mathrm{AG}) 19$ & $\begin{array}{l}\text { F:TATCTGTCGCAGGAAGGATG } \\
\text { R:GAAGCCAATTCCTCAAAGATG }\end{array}$ & 58 & 235 \\
\hline PGCT093B & $(\mathrm{GA})_{16}$ & $\begin{array}{l}\text { F: CCACTTCCCTCCTACCTTCC } \\
\text { R: ACGTCTGCTTGCACCTCTTT }\end{array}$ & 60 & 188 \\
\hline PGCT111 & $(\mathrm{CT}) 22$ & $\begin{array}{l}\text { F:TCCTCCGACCCTTTCTTATC } \\
\text { R:CCCTATCATCCTTCCCATTC }\end{array}$ & 58 & 237 \\
\hline EPS06 & $(\mathrm{CT})_{9}$ & $\begin{array}{l}\text { F: TGGGGATTATCGTTGTCTTCA } \\
\text { R: TCCAAGCTGAACTCGTTCCT }\end{array}$ & 58 & 236 \\
\hline EPS08 & $(\mathrm{AG})_{15}$ & $\begin{array}{l}\text { F: TAATCCCATTCCAAACAAGTCC } \\
\text { R: ATATTGACGGAGGCTTCACTGT }\end{array}$ & 57 & 199 \\
\hline EPS09 & $(\mathrm{AG}) 18$ & $\begin{array}{l}\text { F:TTCCCGAGAAAGTTGCATATCT } \\
\text { R:TAGTCCGTGAGGATTTTGTCCT }\end{array}$ & 58 & 205 \\
\hline EPS19 & $\mathrm{TC})_{13}($ & $\begin{array}{l}\text { F: AAATCGCATCCCTCCGTCT } \\
\text { R: CTGTTCGCCAGGGTAAAGA }\end{array}$ & 63 & 147 \\
\hline ABRII-MP26 & $(\mathrm{AG})_{25}$ & $\begin{array}{l}\text { F: TTTCTCGAAGAATTGGGTAA } \\
\text { R: CTGAGTAAGCTGAGGCTGAT }\end{array}$ & 57 & 160 \\
\hline ABRIIMP42 & $(\mathrm{GA})_{9}$ & $\begin{array}{l}\text { F: GAGCAGAGCAATTCAATCTC } \\
\text { R: AACAATTTCCCATGTTTGAC }\end{array}$ & 57 & 220 \\
\hline
\end{tabular}

Shown for each primer pair are the forward $(\mathrm{F})$ and reverse $(\mathrm{R})$ primer sequences, repeat motif, annealing temperature (Ta) and expected product size respectively.

Table 4 The results of primer screening for 39 pomegranate samples.

\begin{tabular}{|c|c|c|c|c|c|}
\hline Locus Name & $\mathrm{N}$ & Ho & $\mathrm{He}$ & $\mathrm{Rp}$ & PIC \\
\hline PGCT015 & 3 & 0.04 & 0.14 & 0.30 & 0.20 \\
\hline PGCT028 & 3 & 0.30 & 0.34 & 0.82 & 0.36 \\
\hline PGCT080 & 4 & 0.05 & 0.53 & 1.94 & 0.40 \\
\hline PGCT088 & 4 & 0.92 & 0.62 & 1.07 & 0.60 \\
\hline PGCT109 & 4 & 0.84 & 0.57 & 1.07 & 0.76 \\
\hline PGCT087 & 3 & 0.35 & 0.32 & 0.82 & 0.30 \\
\hline PGCT093A & 4 & 0.76 & 0.56 & 0.97 & 0.68 \\
\hline PGCT093B & 3 & 0.61 & 0.56 & 1.43 & 0.64 \\
\hline PGCT111 & 2 & 0.47 & 0.39 & 1.02 & 0.38 \\
\hline EPS06 & 2 & 0.79 & 0.50 & 0.46 & 0.28 \\
\hline EPS08 & 3 & 0.69 & 0.61 & 1.28 & 0.66 \\
\hline EPS09 & 2 & 0.51 & 0.45 & 0.97 & 0.14 \\
\hline EPS19 & 2 & 0.17 & 0.35 & 0.71 & 0.90 \\
\hline ABRII-MP26 & 4 & 0.17 & 0.20 & 0.46 & 0.24 \\
\hline ABRIIMP42 & 3 & 0.87 & 0.50 & 0.41 & 0.48 \\
\hline Mean & 3.06 & 0.50 & 0.56 & - & 0.45 \\
\hline
\end{tabular}

N, number of alleles; Ho, observed heterozygosity; He, Expected heterozygosity; Rp, resolving power; PIC, polymorphic information content values are given for each locus. The locus names are same as given in Table 3.

Table 5 Analysis of Molecular Variance (AMOVA) of 39 selected pomegranate accessions

\begin{tabular}{l|ccccc}
\hline \multicolumn{1}{c|}{ Source of variation } & df & SS & MS & Est. Var. & $\%$ \\
\hline Among cultivars & 4 & 164.80 & 41.20 & 3.31 & 17 \\
Within cultivars & 34 & 543.55 & 15.98 & 15.98 & 83 \\
Total & 38 & 708.35 & & 19.29 & 100 \\
\hline
\end{tabular}




\section{M1234567891011 121314151617181920212223242526272829303132333435363738 39}

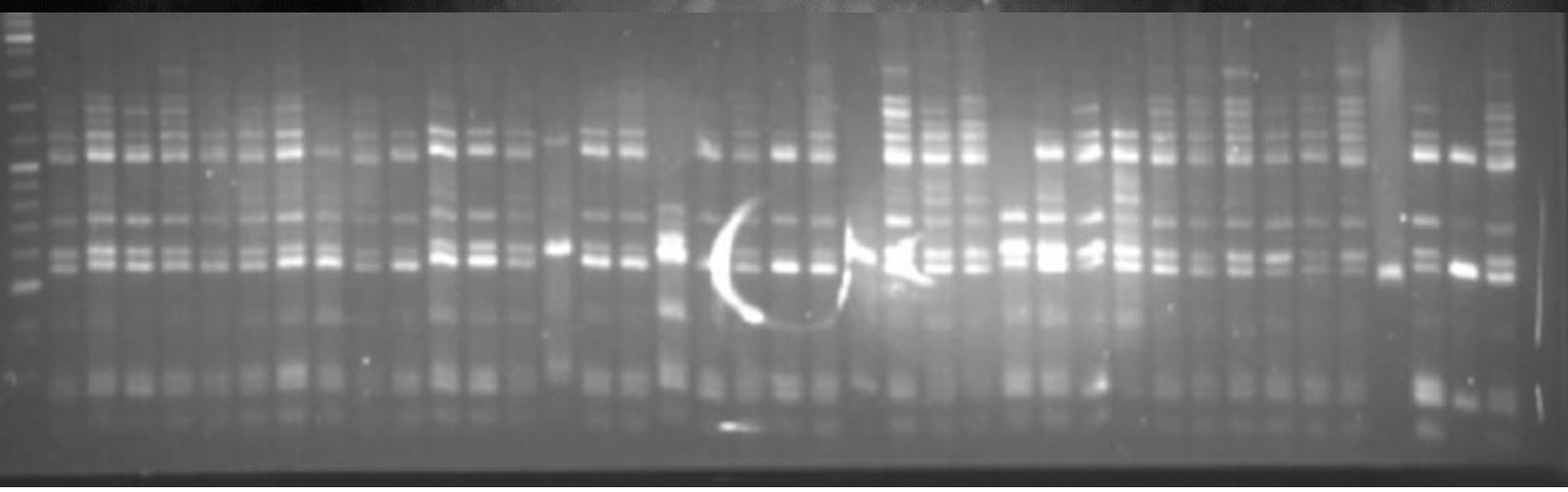

Fig. 1 ISSR amplification profile for primer UBC868 on 39 samples of pomegranate contains 7 pomegranate genotypes: M: 100bp DNA ladder, (1- 9) Malas Saveh, (10- 18) Alak Yousef Khani, (19-27) Ghojagh Qom, (27- 36) Chandab Varamin, 37 black pomegranate, 38 Seedless white skin, 39 Sweet white skin.

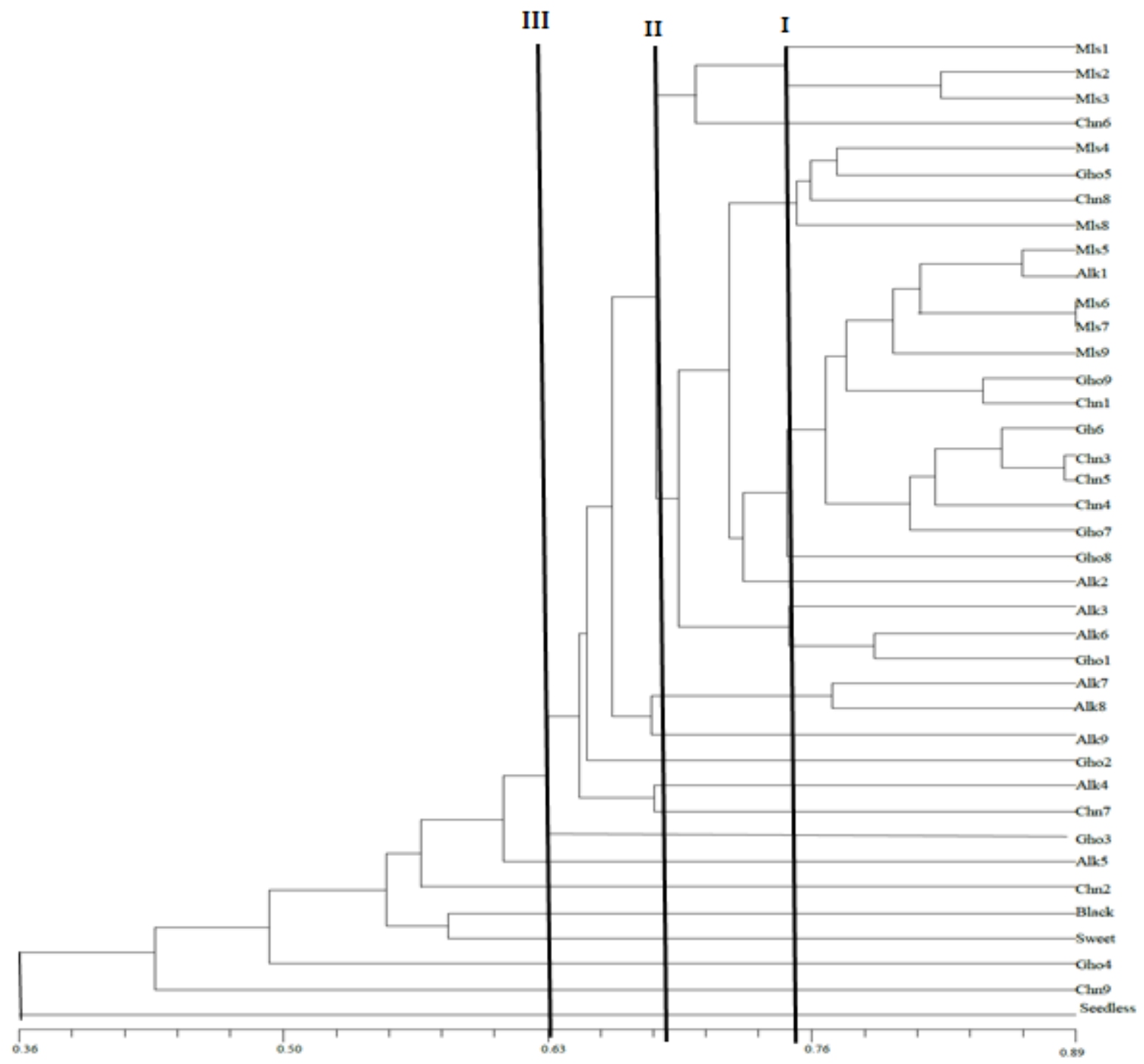

Fig. 2 Cluster of 39 pomegranate samples based on Jaccard's similarity matrix from the ISSR data. 


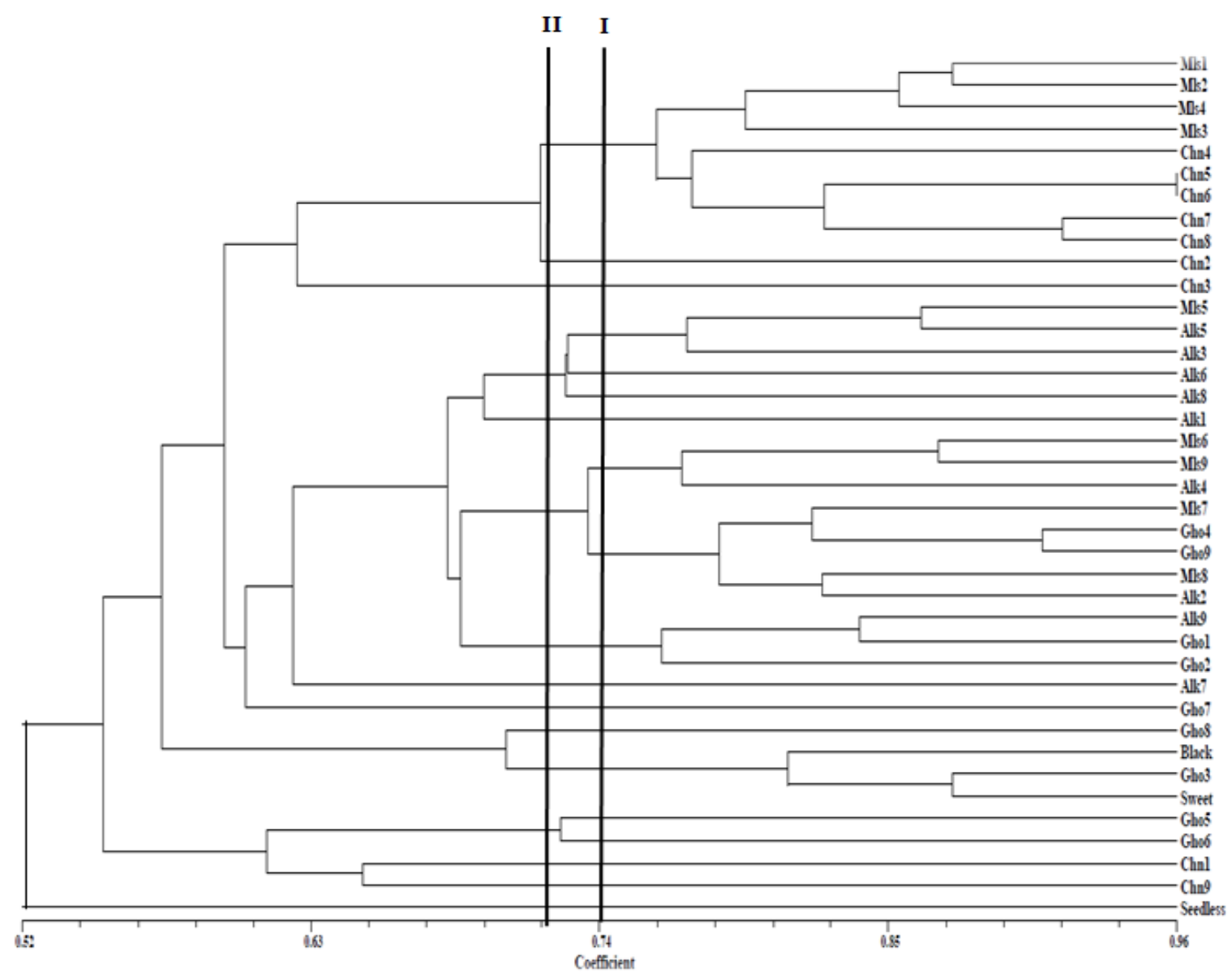

Fig. 3 UPGM dendrogram of 39 pomegranate samples. based on Jaccard's similarity matrix from the SSR data.

\section{Analysis of Molecular Variance (AMOVA)}

Analysis of molecular variance by applying molecular data of 39 pomegranate samples and selecting 13 ISSR and 15 SSR primers resulted in a genetic diversity of $17 \%$ among the cultivated accessions growing in 4 different regions with different ecological history, while $83 \%$ of molecular diversity was found within these cultivars (Table 5). These results are in accordance to the findings of Narzary et al. (2010) and may be due to the reason that these regions had a high genetic overlap as a result of relatively high gene flow. This reasoning is further strengthened by the clonal propagation of pomegranate accessions (Parvaresh et al. 2012; Ajal et al. 2014).

\section{Conclusions}

To the best of our knowledge, this is the first time that clonal diversity has been reported for P. granatum L. Iran hosts a great genetic diversity of $P$. granatum and more than 760 Iranian genotypes are collected at Iranian national pomegranate in Yazd, Iran. Identification of genetic variation within cultivars (clones of each cultivar) is very important, because some of them can have unique characteristics that might be economically more important.
Our results clearly demonstrate that Iranian pomegranate cultivars have many clones and that ISSR and SSR markers can be used to identify clonal diversity within cultivars. The used ISSR primers showed a higher percentage of polymorphic bands of $83.23 \%$ compared to the finding in Iran by Noormohammadi et al (2012), (Narzary et al., 2010), Talebi Bedaf et al. (2011), and Ajal et al, (2014) in Morocco. In addition, due to high PIC value obtained in the majority of ISSR and SSR markers, these markers could be used for identification and characterization of each pomegranate cultivar maybe, only due to the high number of SSR and ISSR loci studied, supporting the results obtained by Ebrahimi et al. (2010); Hasnaoui et al. (2010b); Pirseyedi et al. (2010); Soriano et al. (2011) that present low PIC values. Cophenetic correlation between Dice similarity and Jacard's similarity coefficient dendrogram showed the highest value $(\mathrm{r}=0.86)$ in SSR data and in ISSR data $(\mathrm{R}=$ 0.92). The correlation between ISSR and SSR showed a significant retrogression $\left(\mathrm{R}^{2}=0.41\right)$ (Noormohammadi et al., 2012).

In the study herein, the result of ordination and cluster analysis (ISSR and SSR) clearly showed that there exists a high degree of genetic diversity within each cultivar, Therefore samples which were collected as a genotype can belong to other cultivars. This investigation suggested 
that almost all the Iranian cultivars share similar genetic background, and are likely derived from a small number of introductions in ancient times (Hasnaoui et al., 2011b; Nafees et al., 2015). The outcomes of Jacard's dendrogram in both ISSR and SSR primers can indicate a problem of homonymy or synonymy in the cultivars appellation. Hence, despite the relative high degree of diversity, the Iranian pomegranate germplasm represents a quite homogenous population, similar results have been reported by Ajal et al., (2014); Nafees et al., (2015). In accordance with obtained results in this study there have been genetic differences within each cultivar, and these distinctions may be caused by different environmental conditions, wrong naming by pomegranate growers and mutation that cause the incorrect name.

\section{References}

Ajal EA, Jbir R, Melgarejo P, Hernández F, Haddioui A, \& Hannachi AS. 2014. Efficiency of inter simple sequence repeat (ISSR) markers for the assessment of genetic diversity of Moroccan pomegranate (Punica granatum L.) cultivars. Biochem. Syst. Ecol., 56:24-31

Bassam BJ, Caetano-Anolles G. 1993. Silver staining of DNA in polyacrylamide gels. Appl. Bioch. and Biotech., 42:181-188

Behzadi Shahrbabaki H. 1998. Genetic diversity of pomegranate genotypes in Iran. Nashr Amoozesh Keshavarzi pp 265.

Curro S, Caruso M, Distefano G, Gentile A, La Malfa S. 2010. New microsatellite loci for pomegranate, Punica granatum (Lythraceae). Am. J. Bot., 1: 58-60.

Ebrahimi S, Sayed-Tabatabaei BE, Sharifnabi B. 2010. Microsatellite isolation and characterization in pomegranate (Punica granatum L.). Iran. J. Biotechnol., 8: 159-163

Gil MI, Barberan FAT, Pierce BH, Holcroft DM, Kader AA. 2000 Antioxidant activity of pomegranate juice and its relationship with phenolic composition and processing. J. Agric. Food. Chem., 48: 4581-89

Gilbert JE, Lewis RV, Wilkinson MJ, Galigari PDS. 1999 Developing and appropriate strategy to assess genetic variability in plant germplasm. TAG Theo. Appl.Genet., 98: 1125-1131.

Hasnaoui N, Buonamici A, Sebastiani F, Mars M, Trifi M, Vendramin GG. 2010b. Development and characterization of SSR markers for pomegranate (Punica granatum L.) using an enriched library. Conservation. Genet. Resour., 2: 283-285

Hasnaoui N, Mars M, Chibani J, Trifi M. 2010a. Molecular Polymorphisms in Tunisian Pomegranate (Punica granatum L.) as Revealed by RAPD Fingerprints. Diversity. 2: 107-114

Jbir R, Hasnaoui N, Mars M, Marrakchi M, Trifi M. 2008. Characterization of Tunisian pomegranate (Punica granatum L.) cultivars using amplified fragment length polymorphism analysis. Sci. Hort., 115: 231-237

Koohi-Dehkordi M, Seyed-Tabatabaei BE, Yamchi A, DaneshShahraki A. 2007. Microsatellite markers in pomegranate. Acta. Hort., 760: 179-183

Mars M, Marrakchi M. 2000. Diversity of pomegranate (Punica granatum L.) germplasm in Tunisia. Gene. Resour. Cro. Evolu., 46: 461-467

Marshall TC, Slate J, Kruuk L, Pemberton JM. 1998. Statistical confidence for likelihood-based paternity inference in natural populations. Mol. Ecol., 7: 639-655

Moslemi M, Zahravi M, Bakhshi Khaniki G. 2010.Genetic diversity and population genetic structure of pomegranate (Punica granatum L.) in Iran using AFLP markers. Sci. Hort., 126: 441447

Nafees M, Jaskani JM, Ahmed S, Awan FS. 2015. Morphomolecular characterization and phylogenetic relationship in pomegranate germplasm of Pakistan. Pak. J. Agri. Sci., 52: $97-$ 106
Narzary D, Rana TS, Ranade SA. 2010. Genetic diversity in intersimple sequence repeat profiles across natural populations of Indian pomegranate (Punica granatum L.). Plant. Biol., 12: $806-813$

Noormohammadi Z, Parvini F, Sheidai M, Vazifeshenas MR. 2010. Further study of morphological and molecular diversity in 18 pomegranate landraces of Iran. Gene Conserve., 9: 189-200

Noormohammadi Z, Fasihee A, Homaee-Rashidpoor S, Sheidai M, Baraki SG, Mazooji A, Tabatabaee-Ardakani SZ. 2012. Genetic variation among Iranian pomegranates (Punica granatumL.) using RAPD, ISSR and SSR markers. Australian. J Crop. Sci., 2: 268-275

Owais SJ, Abdel-Ghani AH. 2016. Evaluation of Genetic Diversity among Jordanian Pomegranate Landraces by Fruit Characteristics and Molecular Markers 2. Int. J. Agric. Biol., 18: 393-402.

Parvaresh M, Talebi M, Sayed-Tabatabaei B. 2012. Molecular diversity and genetic relationship of pomegranate (Punica granatum L.) genotypes using microsatellite markers. Sci. Hortic., 138: 244-252

Pirseyedi SM, Valizadehghan S, Mardi M, Ghaffari MH, Mahmoodi P, Zahravi M, Zeinalabedini M, Khayam Nekoui SM. 2010. Isolation and Characterization of Novel Microsatellite Markers in Pomegranate (Punica granatum L.). Int. J. Mol. Sci., 11: 2010-2016

Prevost A, Wilkinson MJ. 1999. A new system of comparing PCR primers applied to ISSR fingerprinting of potato cultivars. Theor. Appl. Genet., 98: 107-112

Rohlf FG. 2000. NTsys-pc numerical taxonomy and multivariate system version 2.0 Applied. Biostatistics. Inc, New York, USA

Sarkhosh A, Zamani Z, Fatahi R, Hassani ME, Wiedow C, Buck E, Gardiner SE. 2011. Genetic diversity of Iranian soft-seed pomegranate genotypes as revealed by fluorescent-AFLP markers. Physi. Mol. Bio. Plant., 17: 305-311

Sheidai M, Noormohammadi Z. 2005. Chromosome pairing and unreduced Gamete formation in nineteen pomegranate (Punica granatum L.) cultivars. Cytologia., 70: 257-265

Sheidai M, Noormohammadi Z, Saneghi A, Shahryari ZH. 2007. RAPD analysis of eleven Iranian pomegranate (Punica granatum L.) cultivars. Acta. Biol. Szeged., 51: 61-64

Shukla M, Gupta K, Rasheed Z, Khan KA, Haqqi TM. 2008. Bioavailable constituents or metabolites of pomegranate (Punica granatum L.) preferentially inhibit COX2 activity ex vivo and IL-1beta-induced PGE2 production in human chondrocytes in vitro. J. Inflammation., 5: 1-9

Sneath PHA, Sokal RR.1973. Numerical Taxonomy. WH Freeman, San Francisco

Soriano JM, Zuriaga E, Rubio P, Lla'cer G, Infante R, Badenes ML. 2011. Development and characterization of microsatellite markers in pomegranate (Punica granatum L.). Mol. Bre., 27: $119-128$

Talebi Badaf M, Baharmasoud SB, Yamchi A. 2011. Evaluation of genetic diversity among Iranian pomegranate (Punica granatum L.) cultivars using ISSR and RAPD markers. J. Taxo. Bios., 8: 33-44

Vroh Bi L, Harvengt A, Chandelier G, Mergeai P, Jardin Du. 1996. Improved RAPD amplification of recalcitrant plant DNA by the use of activated charcoal during DNA extraction. J Plant. Bre., 155: 205-206

Yeh FC, Yang RC, Boyle T. 1997. Population Genetic analysis (POPGENE 1.31). A joint project of University of Alberta and Center for International Forestry Research.

Yuan Zh, Yin Y, Qu J, Zhu L, Li Y. 2007. Population genetic diversity in Chinese pomegranate (Punica granatum L.) cultivars revealed by fluorescent-AFLP markers. J Genet. Genom., 34: 1061-1071

Zamani Z, Adabi M, Khadivi-Khub A. 2013. Comparative analysis of genetic structure and variability in wild and cultivated pomegranates as revealed by morphological variables and molecular markers. Plant. Syst. Evol., 299: 1967-1980. 